\title{
Experimental investigations on heat transfer characteristics of pulsating single-phase liquid flow and two-phase Taylor bubble flow through a minichannel
}

\author{
KALPAK SAGAR and HEMANTKUMAR B MEHTA* \\ Department of Mechanical Engineering, Sardar Vallabhbhai National Institute of Technology, Surat 395007, \\ India \\ e-mail: hbm@med.svnit.ac.in; hemantbmehta@gmail.com
}

MS received 24 January 2017; revised 21 June 2017; accepted 7 September 2017; published online 28 March 2018

\begin{abstract}
Experimental investigations are reported for pulsating Taylor bubble (PTB) flow through a $2.12 \mathrm{~mm}$ horizontal circular minichannel. Air and water are used as working fluids. A T-junction is used to generate Taylor bubble flow in a minichannel. The superficial gas velocity $\left(U_{S G}\right)$ is kept as $0.0472 \mathrm{~m} / \mathrm{s}$. The superficial liquid velocity $\left(U_{S L}\right)$ is kept as 0.0472 and $0.0708 \mathrm{~m} / \mathrm{s}$. The pulsating liquid flow is generated by developing a pulse generator circuit. The investigations are carried out for various pulsating flow frequencies of $0 \mathrm{~Hz}$ (continuous flow), 0.1, 0.25, 0.5, 1 and $2 \mathrm{~Hz}$, which correspond to Womersley number $\left(W_{o}\right) 0,0.84,1.39$, $1.88,2.65$ and 3.75, respectively. Heat transfer enhancement is found to be negligible (less than 1\%) for pulsating laminar liquid flow through the minichannel. On the contrary, heat transfer is observed to decrease by $35 \%$ for PTB flow compared with continuous Taylor bubble (CTB) flow for imposed frequency of pulsation up to $1 \mathrm{~Hz}$.
\end{abstract}

Keywords. Taylor bubble flow; pulsation frequency; heat transfer; minichannel.

\section{Introduction}

Miniaturization in electronic gadgets becomes instrumental for the rapid industrial development. However, it increases the requirement of high heat flux removal techniques. Various active and passive cooling techniques are reported in literature for the efficient thermal management of the miniaturized electronic device. A pulsating heat pipe (PHP) has evolved as an efficient cooling technique after its invention by Akachi [1, 2]. PHP has been investigated by various researchers due to its fascinating features in terms of manufacturing and operation. It works as a passive heat transfer system involving intricate phase change processes. Net heat transfer in PHP is governed by the distribution of phases in a minichannel, pulsating flow and phase change process [3]. Taylor bubble flow is the commonly observed two-phase flow pattern in PHP with prevailing oscillating frequency in the range of $0.1-3 \mathrm{~Hz}$ [4]. The major contribution of heat transfer is sensible heat transfer compared to latent heat transfer [5]. The flow patterns developed and heat transfer mechanism in a PHP are subject to various parameters such as applied thermal gradient, filling ratio and thermo-physical properties of

*For correspondence the working fluid [6]. Moreover, local heat transfer is governed by velocity, shape and pulsating frequency of Taylor bubble flow [7, 8]. Therefore, PHP is considered to possess complex thermo-hydrodynamics and required to be understood carefully. Similar kind of flow conditions can be developed and studied independently without phase change process to realize the influence on PHP heat transfer under adiabatic condition. Adiabatic Taylor bubble flow conditions followed by diabatic conditions with and without liquid pulsations are logical and practical steps to identify intricate local transport phenomena. Mehta and Khandekar [8] reported that mathematical modelling of a PHP can be performed in three stages. In the first stage, the Taylor bubble flow can be investigated in continuous motion without heat transfer for its hydrodynamics. In the second stage, the continuous motion of Taylor bubble can be investigated with heat transfer and pulsation without phase change. After acquiring sufficient information through non-boiling Taylor bubble flow, phase change heat transfer can be incorporated in the third stage to complete the analysis for the development of mathematical model of PHP.

With this motivation, Mehta and Banerjee [9] have performed experimental investigations on continuous Taylor bubble (CTB) flow through a $2.12 \mathrm{~mm}$ circular minichannel. The research work was carried out to investigate the 
influence of inlet flow parameters on the hydrodynamics of CTB flow under adiabatic and diabatic conditions. The objective of the present research work is to investigate the influence of imposed frequency of pulsation on two-phase flow (Taylor bubble flow)-induced heat transfer through a $2.12 \mathrm{~mm}$ circular horizontal minichannel.

\section{Experimental set-up}

The experimental set-up developed by Mehta and Banerjee [9] is shown in figure 1. The set-up was developed to investigate the influence of hydrodynamics of gasliquid two-phase flow through a minichannel under adiabatic and diabatic situations. A schematic diagram of heating section for heat transfer experiments is shown in figure 2. Other particular details of the set-up are reported in article [9].

In addition to gas flow circuit, liquid flow circuit, visualizing section and heating section, a pulse generator circuit is developed for the present research work and is shown in figure 2. The pulse generator circuit consists of two solenoid valves, a control panel and a voltage controller. It is installed in the liquid phase circuit. The two solenoid valves (Make: Techno pneumatic; Model: $2 \mathrm{~W}$ 160-15) are electromagnetic and function complementary to each other. Each solenoid valve is 2-way and normally of closed type. The terminal box is used for main power supply to the pulse control panel, which consists of MCB,
RFI/EMI filter and SMPS as shown in figure 3. The SMPS converts $230 \mathrm{~V}$ AC into $24 \mathrm{~V}$ DC, which is supplied to PLC. The PLC is connected to a computer. The PLC gives output based on the program and as per the command given by the SCADA software installed on computer. Step input to each solenoid valve is observed on a DSO and shown in figure 4. Air flow and water flow data are transferred to PLC through a RS-232 serial connection. The frequency of pulsation is set through a PID controller, which controls the opening and closing of solenoid valves through an electronic timer circuit. Fluid flow takes place during ON cycle, which is half of the imposed time scale, and flow completely stops during OFF cycle, which is another half of the imposed time scale.

\section{Results and discussion}

This section discusses the experimental results obtained for continuous and pulsating single-phase liquid flow and twophase Taylor bubble flow through a $2.12 \mathrm{~mm}$ circular minichannel. The experiments are first performed for diabatic single phase liquid flow with continuous and pulsating flow conditions. Two-phase flow experiments are then performed for CTB and pulsating Taylor bubble (PTB) flow under adiabatic and diabatic flow conditions. Uncertainties in operating parameters are calculated based on the Kline and McClintock approach [10]. An Engineering Equation Solver (EES) is used to determine fluid properties and

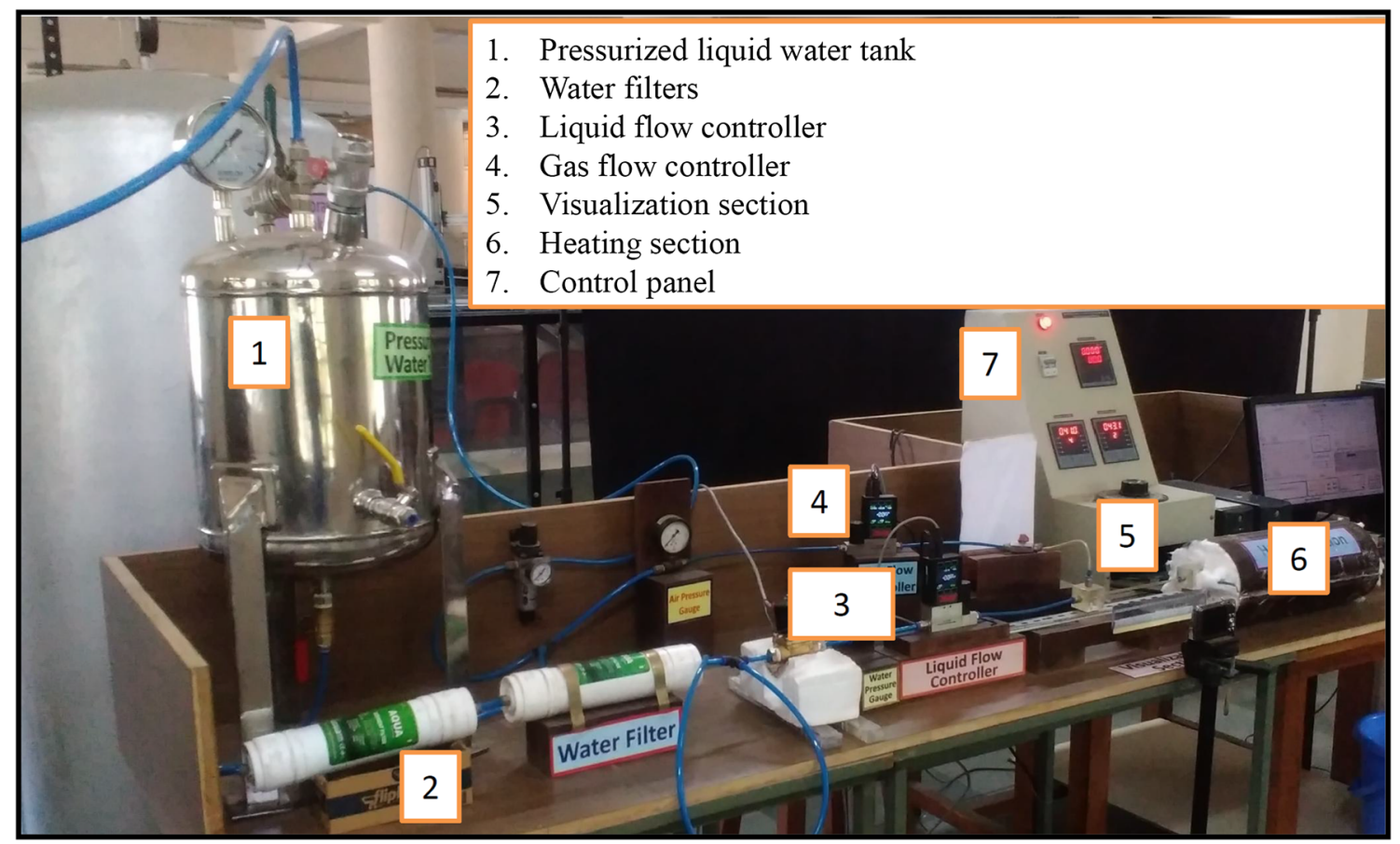

Figure 1. Experimental set-up developed by Mehta and Banerjee [9]. 


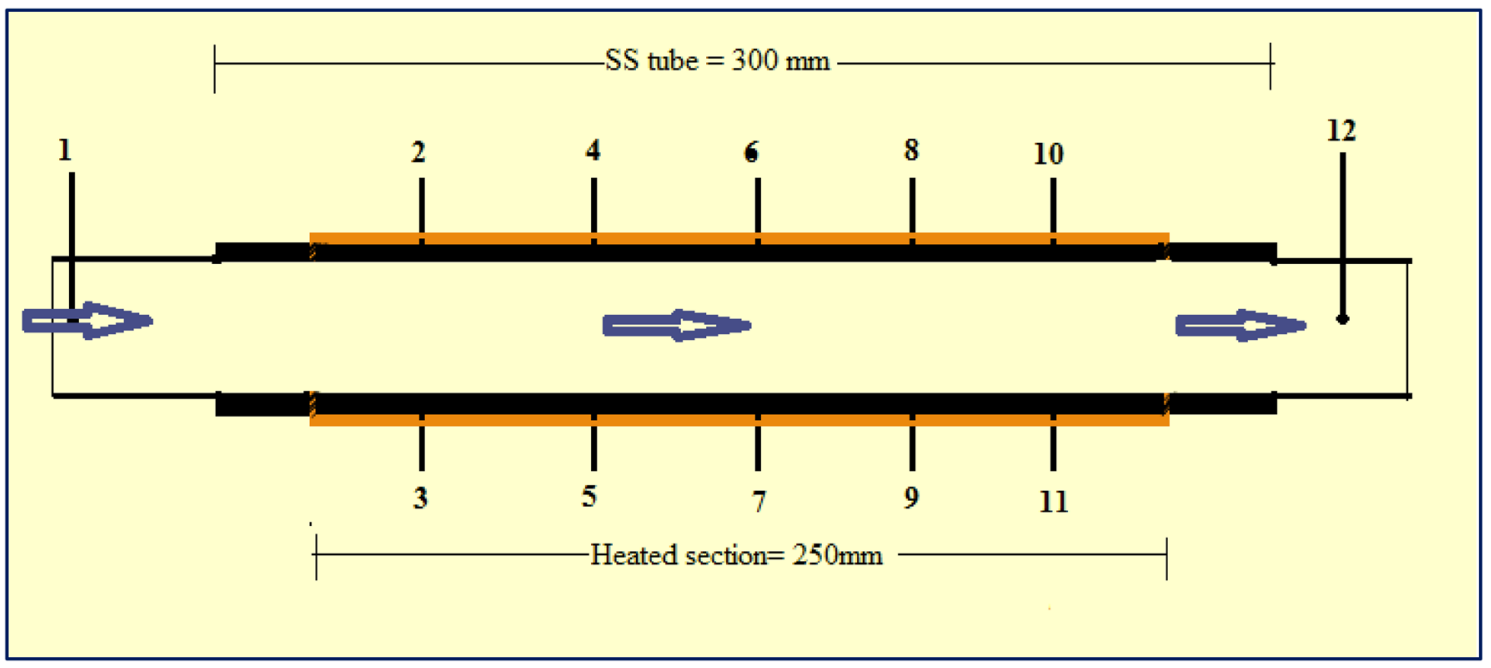

Figure 2. Schematic diagram of heating section with 12 number of RTDs locations.

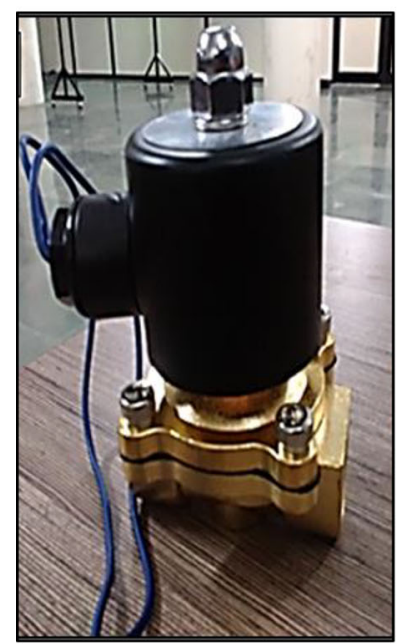

(a)

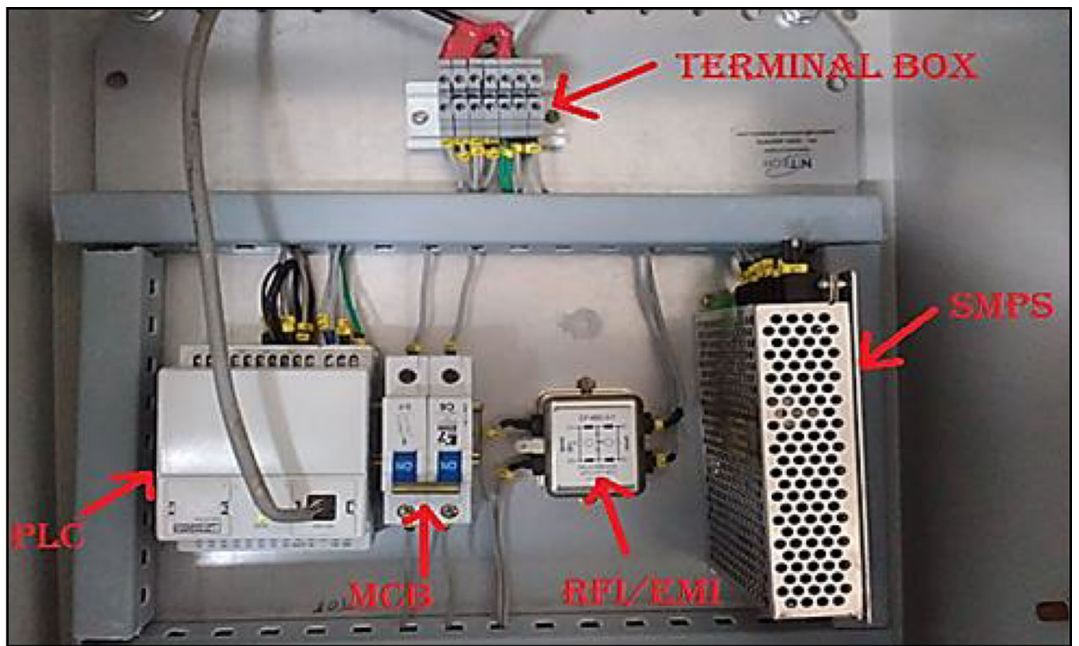

(b)

Figure 3. Pulse generator circuit: (a) solenoid valve and (b) control panel.

to carry out uncertainty analysis. The uncertainty of $\pm 5.24 \%$ is observed for flow velocities, $\pm 3.22 \%$ is observed for Reynolds number, $\pm 2.82 \%$ is observed for heat input and $\pm 6.78 \%$ is observed for Nusselt number.

\subsection{Continuous single-phase flow}

This section discusses the results obtained for continuous single-phase liquid flow through a minichannel. Reynolds number considered is 152 and 285 and wall heat input is set as $10 \mathrm{~W}$. The liquid flow controller is kept at a sufficient distance to attend hydrodynamically fully developed flow condition at the entrance of the heating section. The length of the heating section is $250 \mathrm{~mm}$. The time- averaged wall temperatures $(T)$ are measured at an axial distance $(x)$ of $25,75,125,175$ and $225 \mathrm{~mm}$ from the inlet of the heating zone (figure 2 and article [9]). The dimensionless wall temperature $\left(T_{W}^{*}\right)$, bulk fluid temperature $\left(T_{f}^{*}\right)$ and axial length $\left(L^{*}\right)$ are estimated from Eqs. (1), (2) and (3), respectively:

$$
\begin{gathered}
T_{W}^{*}=k_{f}\left(T-T_{f i}\right) /\left(q_{i} d_{h}\right), \\
T_{f}^{*}=k_{f}\left(T_{b m}-T_{f i}\right) /\left(q_{i} d_{h}\right), \\
L^{*}=x / L .
\end{gathered}
$$

Here, $q_{i}$ is the heat flux of each zone, $k_{f}$ is the thermal conductivity of fluid, $T_{f i}$ is the inlet fluid temperature and $L$ 
is total length of heating section. Local heat transfer coefficient and Nusselt number are experimentally estimated based on Eqs. (4) and (5), respectively.

$$
\begin{gathered}
h_{i}=\frac{Q_{i}}{\pi d_{i} l\left(T_{w, i}-T_{b m, i}\right)}, \\
N u_{i}=h_{i} d_{i} / k_{f} .
\end{gathered}
$$

The axial downstream position of the heated section in dimensionless form is defined by the inverse Graetz number $\left(x^{*}\right)$ and can be estimated as per Eq. (6):

$$
x^{*}=\frac{x}{\operatorname{Re} \cdot \operatorname{Pr} \cdot d_{i}} \text {. }
$$

Here, $x$ is the axial length from the heating section. The theoretical value of Nusselt number is estimated using Eq. (7) proposed by Muzychka and Yovanovich [11]:

$$
N u_{x, \text { pois }}=\left[\left(1.302 / x^{*(1 / 3)}\right)^{5}+(4.36)^{5}\right]^{1 / 5}
$$

Non-dimensional wall and bulk fluid temperatures as a function of dimensionless axial length are shown, respectively, in figure $5 \mathrm{a}$ and $\mathrm{b}$. Local Nusselt number variation as a function of inverse Graetz number is shown in figure $6 \mathrm{a}$ and $b$. The trend observed from figures 5 and 6 confirms that the constant heat flux condition is attained in the present sets of experiments and observed to be in agreement with the theoretical prediction of local Nusselt number (Eq. (7)) of Muzychka and Yovanovich [11].

\subsection{Pulsating single-phase flow}

The basic meaning of pulsatile flow is a kind of flow that repeats itself after a particular interval of time. It can also be called as a periodic flow. This type of flow is mainly characterized by the frequency of pulsation. After verifying the heat transfer set-up for constant wall heat flux condition, the pulsating laminar liquid flow through a minichannel is performed and discussed in this section. The pulsation frequencies are set as $0.1,1.0$ and $2.0 \mathrm{~Hz}$; the Womersley number $\left(W_{o}\right)$ [12] is estimated to be $0.84,2.65$ and 3.75 , respectively. These values of frequency are chosen because pulsatile velocity profiles exhibit different characteristics for $W_{o}>1$ (annular effect, i.e., peak velocity near wall) and $W_{o}<1$ (conventional parabolic profile) [8, 13]. Imposed frequency of pulsation and corresponding parameters such as Womersley number, imposed time scale and thermal diffusivity time scale are tabulated in table 1 . The frequency of pulsation is set through PID controller. Thermal diffusivity time scale represents time required for heat to diffuse throughout volume and provides the importance of conduction over convective heat transfer for pulsating fluid flow.

The influence of pulsating frequency on liquid flow rate as a function of time is plotted in figure $7 \mathrm{a}, \mathrm{b}$ and $\mathrm{c}$ for 0.1 , 1 and $2 \mathrm{~Hz}$ frequency keeping liquid velocity as $0.0472 \mathrm{~m} / \mathrm{s}$, respectively. Figure $8 \mathrm{a}, \mathrm{b}$ and $\mathrm{c}$ is plotted for $0.1,1$ and $2 \mathrm{~Hz}$ frequency keeping liquid velocity as $0.0944 \mathrm{~m} / \mathrm{s}$, respectively. An Alicat Scientific make LC series digital liquid flow controller of 100 CCM (cubic centimetre per minute) is used to control liquid flow rate.

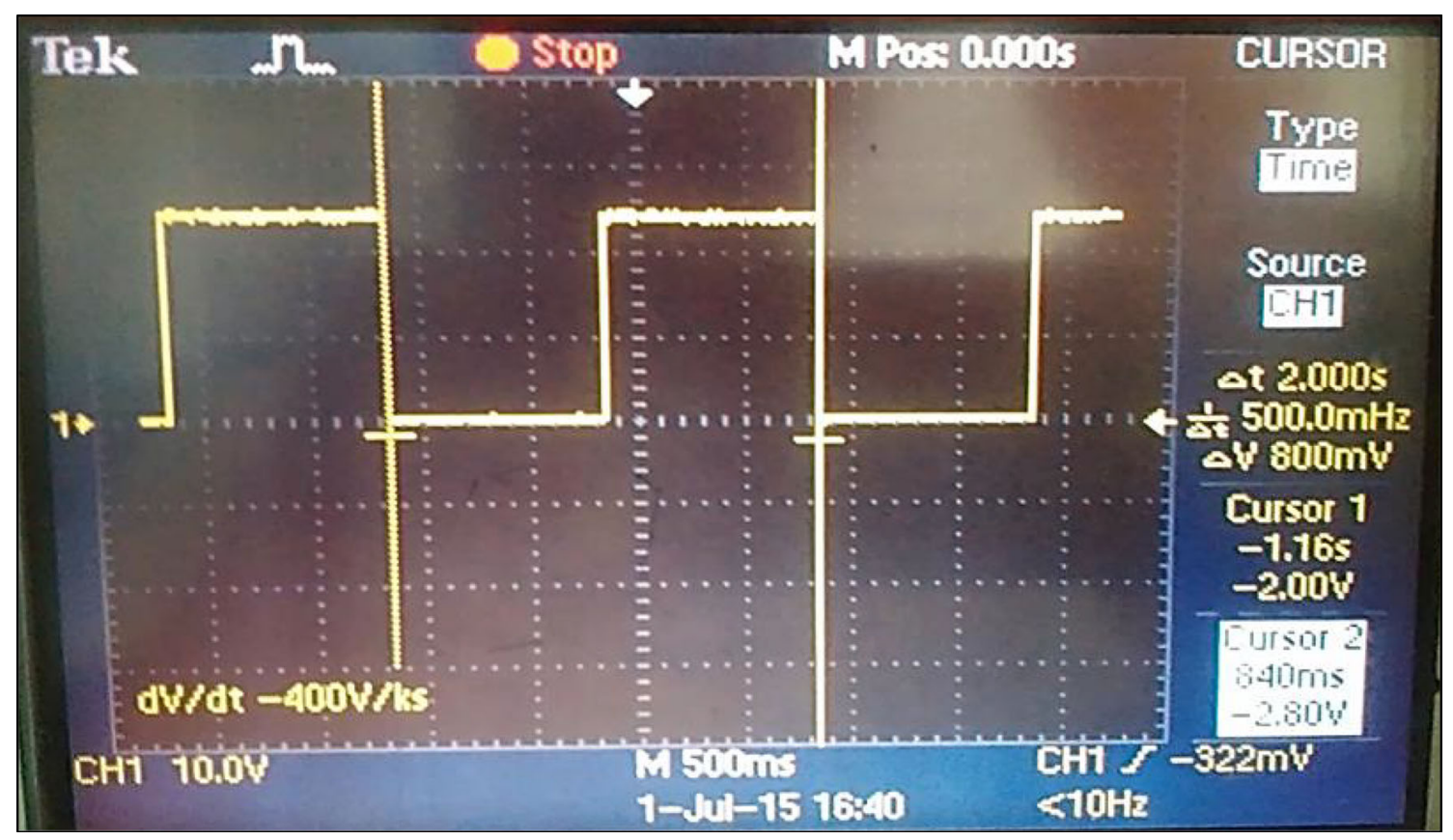

Figure 4. Step input given to solenoid valve observed on DSO. 

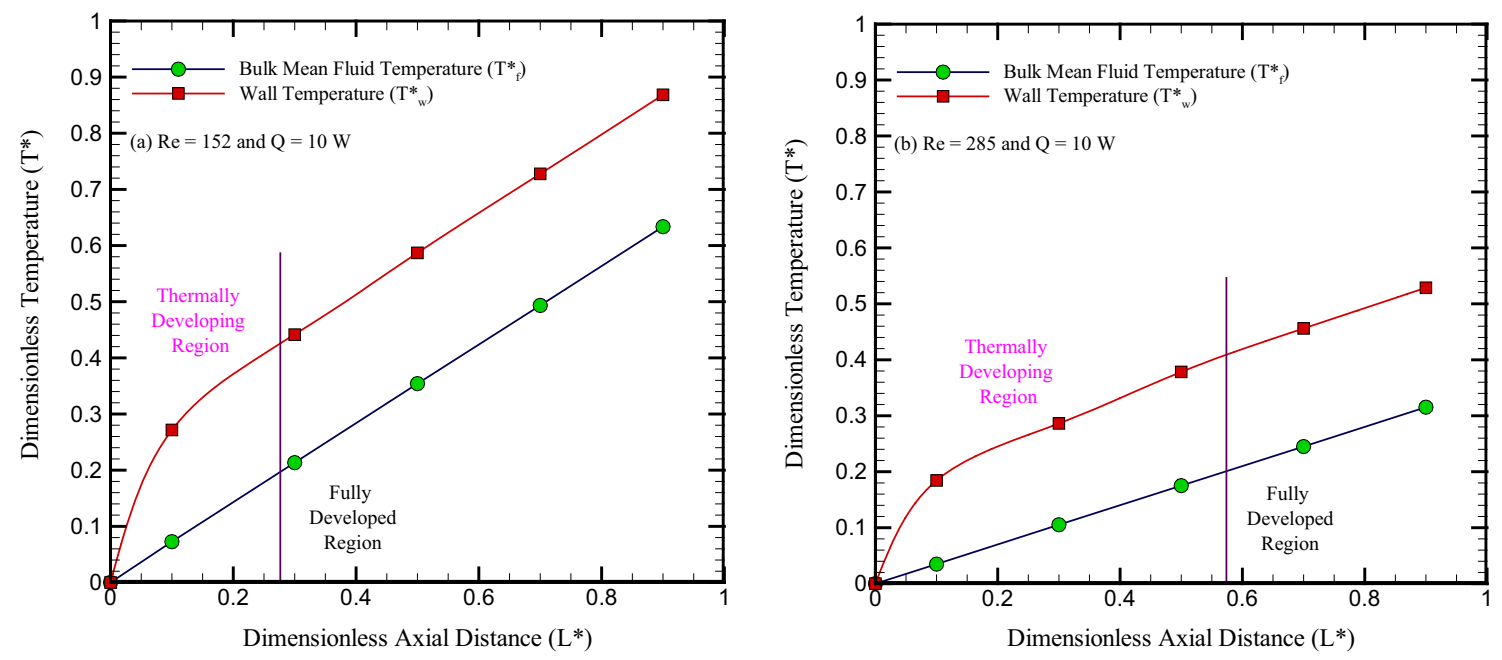

Figure 5. Dimensionless wall and fluid temperature versus dimensionless axial distance.
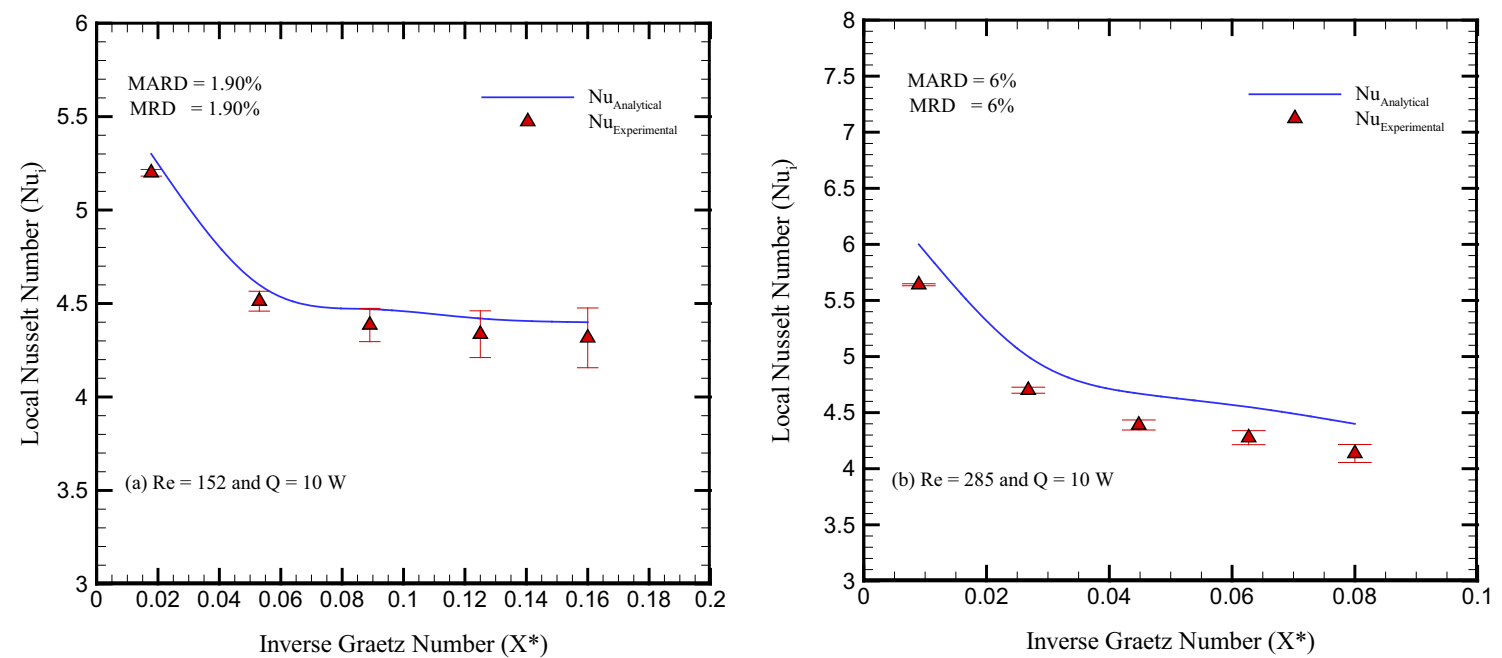

Figure 6. Local Nusselt number variation as a function of inverse Graetz number $\left(x^{*}\right)$.

Table 1. Imposed and thermal diffusivity time scale for imposed pulsation.

\begin{tabular}{lccc}
\hline Imposed pulsation $(\mathrm{Hz})$ & 0.1 & 1 & 2 \\
Womersley number & 0.84 & 2.65 & 3.75 \\
Imposed time scale (s) & 10 & 1 & 0.5 \\
Thermal diffusivity time scale (s) & 34.42 & 34.42 & 34.42 \\
\hline
\end{tabular}

The accuracy of the controller is $\pm 2 \%$. The flow controller has less than $100 \mathrm{~ms}$ control response time, which is higher than the frequency range selected for the experiments. It is observed that for a particular liquid flow rate, increase in pulsation frequency decreases the amplitude of flow at its mean value of 1 . It is also observed that with the increase in flow rate at a specified pulsating frequency, amplitude of flow decreases. It is worth reiterating that the solenoid valve function is controlled with step input (opens at $24 \mathrm{~V}$ DC and closes at $0 \mathrm{~V} \mathrm{DC}$ as shown in figure 3). The expected waveform pattern for liquid differs compared with step input due to the mechanical and thermal inertia of a solenoid valve. However, the measured average flow rate through flow controller during each open cycle is found to be accurate. Figures $7 \mathrm{~d}-\mathrm{f}$ and $8 \mathrm{~d}-\mathrm{f}$ show the FFT analysis for $0.1,1$ and $2 \mathrm{~Hz}$ frequency at 0.0472 and $0.0944 \mathrm{~m} / \mathrm{s}$, respectively. It can be verified that the dominant pulsation frequency of liquid flow is nearly identical to that of imposed frequency of pulsation for all the cases.

Dimensionless wall and bulk fluid temperature variations along non-dimensional axial length as a function of imposed frequency of pulsation $(0,0.1,1$ and $2 \mathrm{~Hz})$ at 


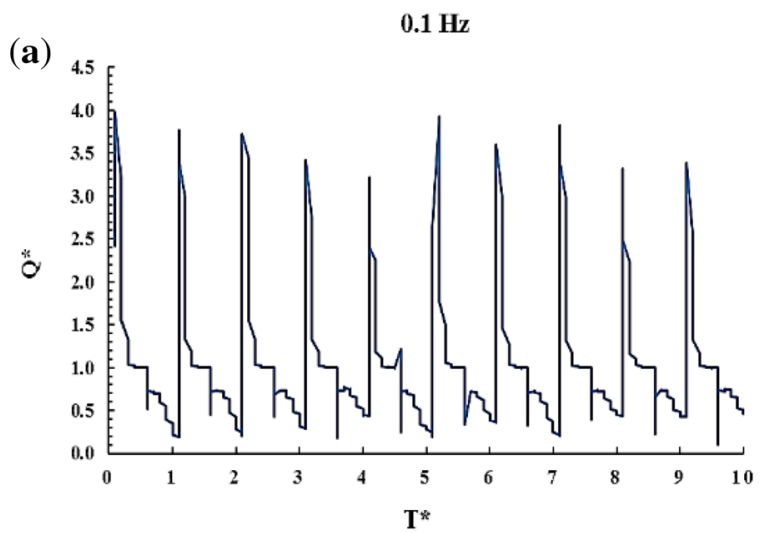

(b)

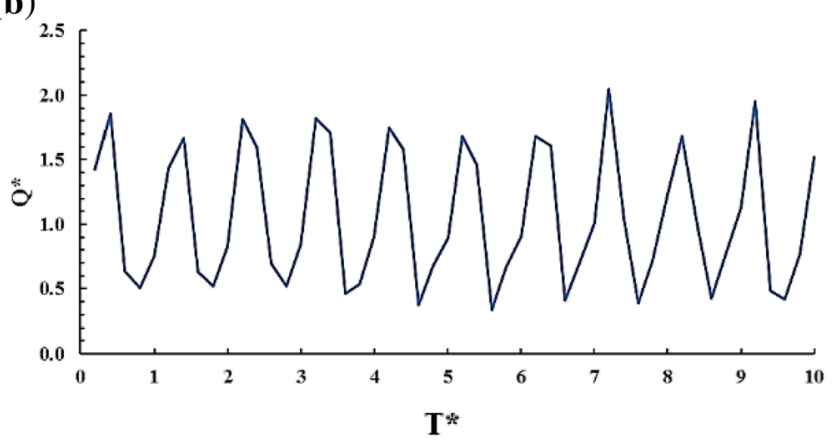

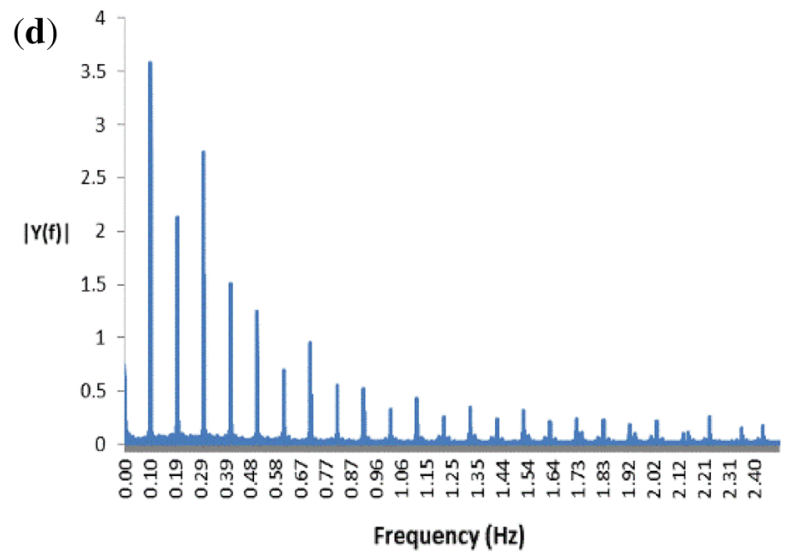

(e)

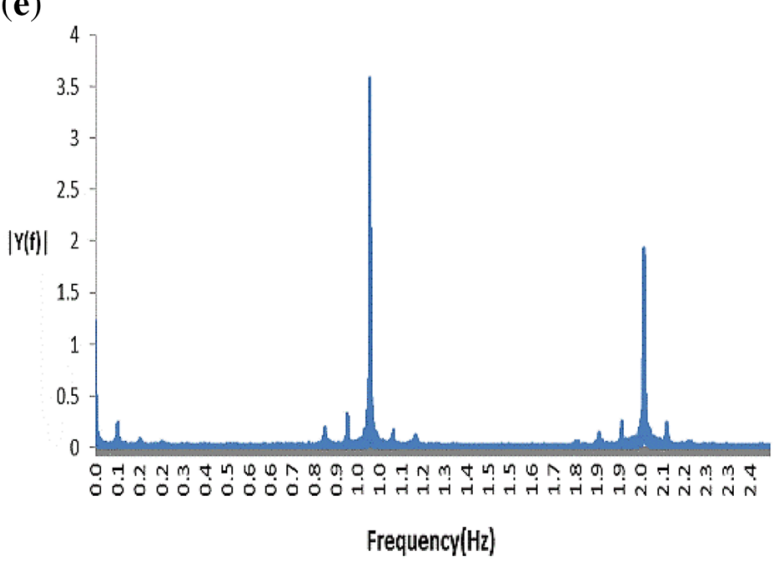

(f)

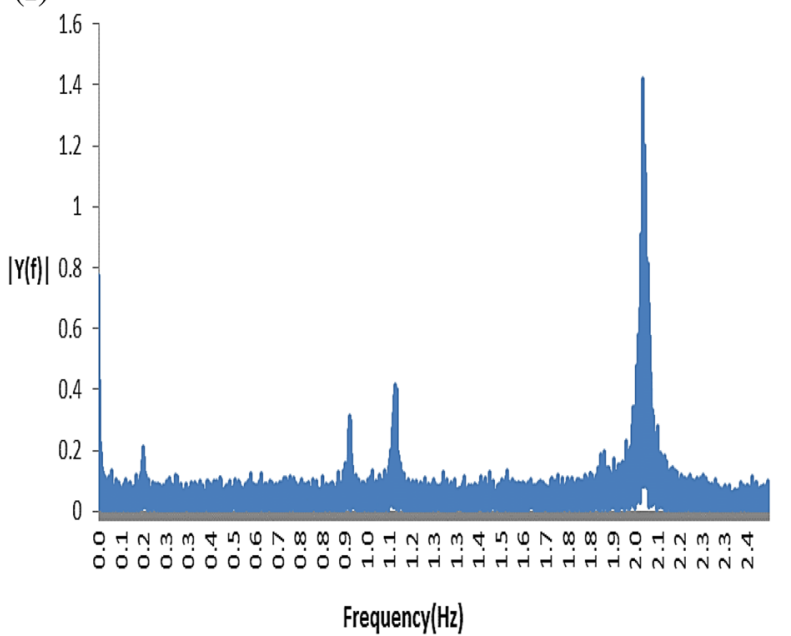

Figure 7. Non-dimensional instantaneous flow rate as a function of time for liquid velocity of $0.0472 \mathrm{~m} / \mathrm{s}$ and its corresponding FFT analysis for (a, d) $0.1 \mathrm{~Hz},(\mathbf{b}, \mathbf{e}) 1 \mathrm{~Hz}$ and (c, f) $2 \mathrm{~Hz}$.

$R e=152$ and $R e=285$ are shown in figure 9. Wall temperatures and bulk fluid temperatures are observed to increase along axial length, ensuring constant heat flux condition at the channel wall. Overall temperature slopes are observed to decrease in figure $9 \mathrm{~b}(R e=285)$ compared with figure 9a $(R e=152)$. This shows better heat transfer with increase in mass flow rate of water. Wall temperature at a typical axial location is observed to decrease with increase in imposed frequency. At low operating frequency (e.g., for $0.1 \mathrm{~Hz}$, off cycle time is $5 \mathrm{~s}$ ) during OFF cycle, time for diffusion heat transfer is sufficient to retain no flow condition in the channel. Hence, heat is conducted to the fluid by constant wall heat flux, which increases wall surface temperature. At 
(a)

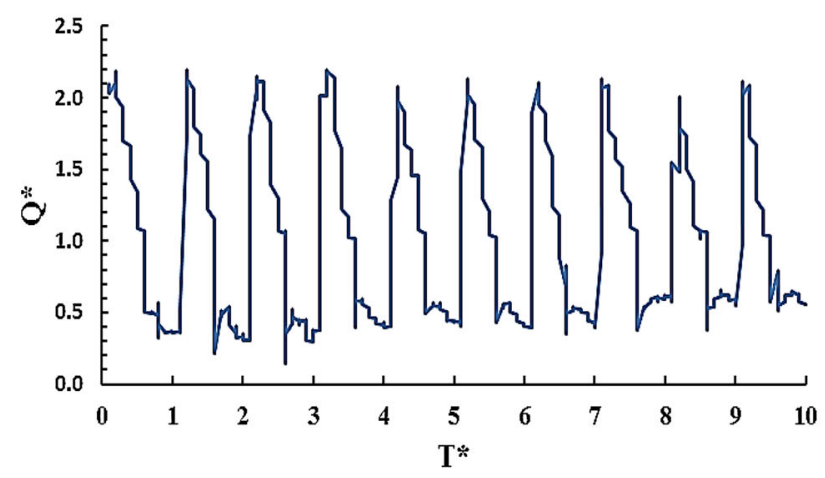

(b)

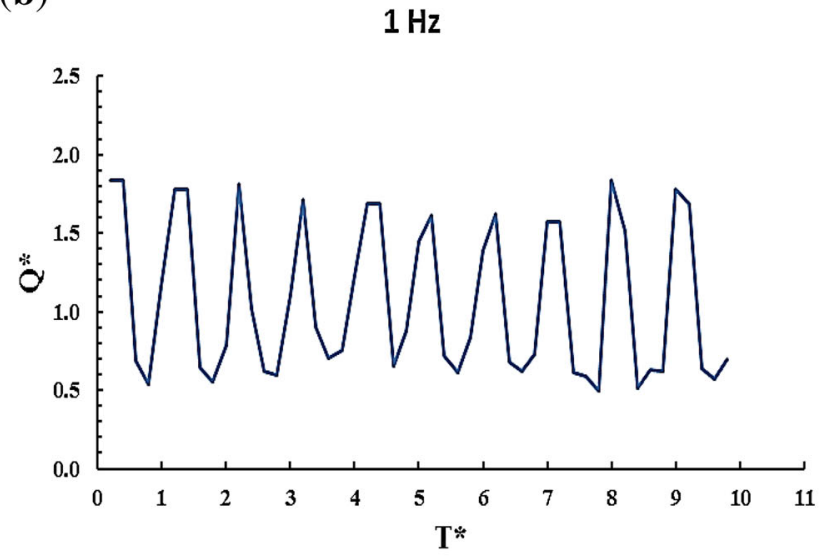

(c)

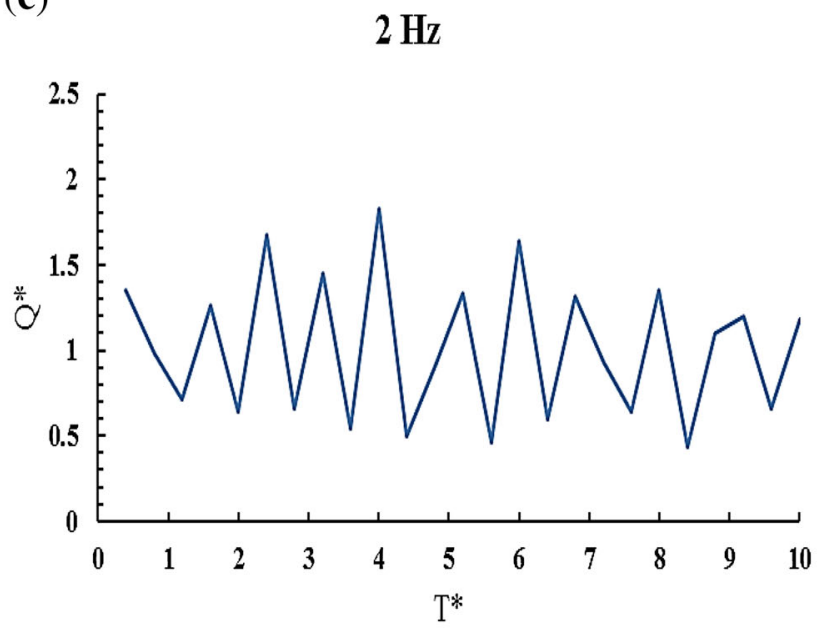

(d)

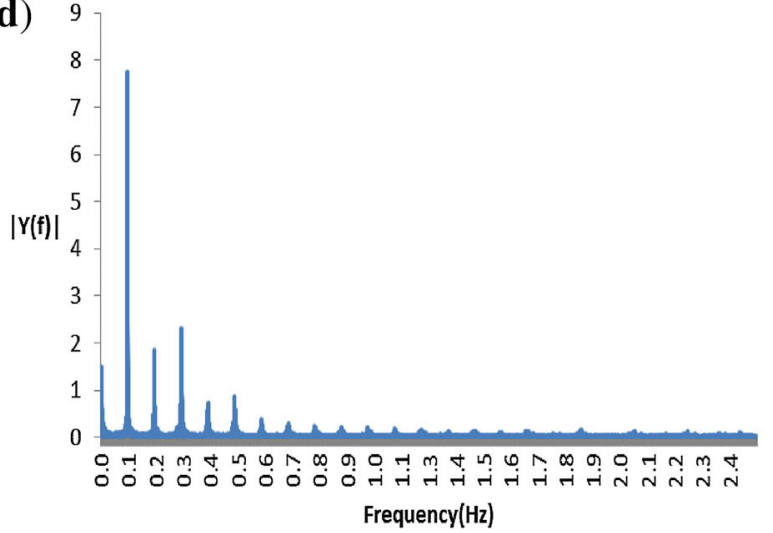

(e) 2.5

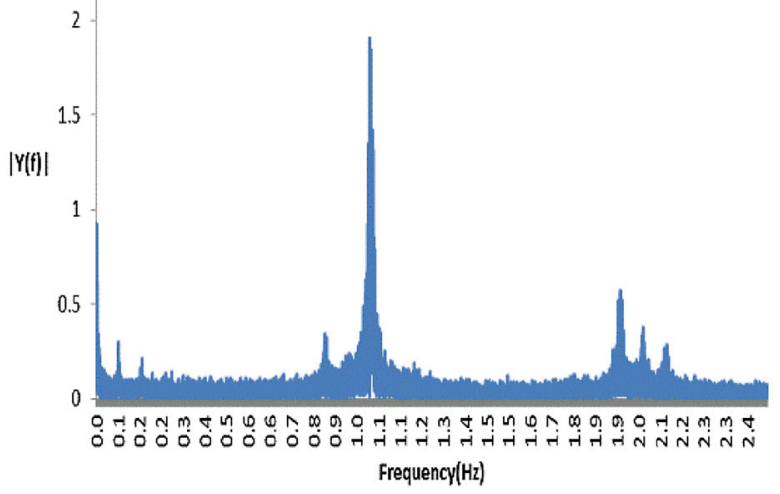

(f)

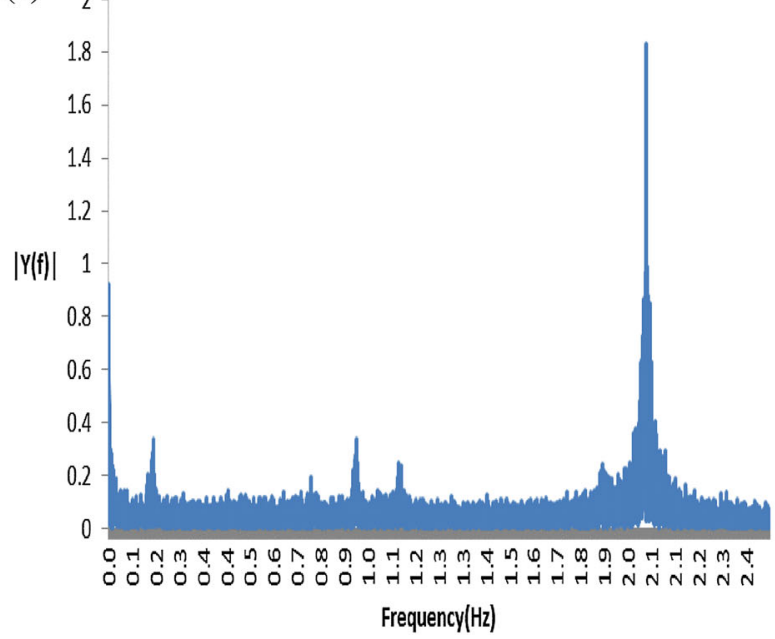

Figure 8. Non-dimensional instantaneous flow rate as a function of time for liquid velocity of $0.0944 \mathrm{~m} / \mathrm{s}$ and its corresponding FFT analysis for (a, d) $0.1 \mathrm{~Hz},(\mathbf{b}, \mathbf{e}) 1 \mathrm{~Hz}$ and (c, f) $2 \mathrm{~Hz}$.

higher imposed frequency of pulsation, i.e., $2 \mathrm{~Hz}$, satisfying no flow condition is difficult on the channel wall due to very low time available for OFF cycle $(0.25 \mathrm{~s})$. Hence, the fluid continuously carries away heat from the wall, which reduces the channel wall temperature. The wall temperature is observed to be higher for imposed frequency of pulsation up to $1 \mathrm{~Hz}$ compared with wall temperature observed for continuous flow $(0 \mathrm{~Hz})$. This is due to the reason that in continuous flow, heat from the channel wall is continuously carried away by the fluid, 

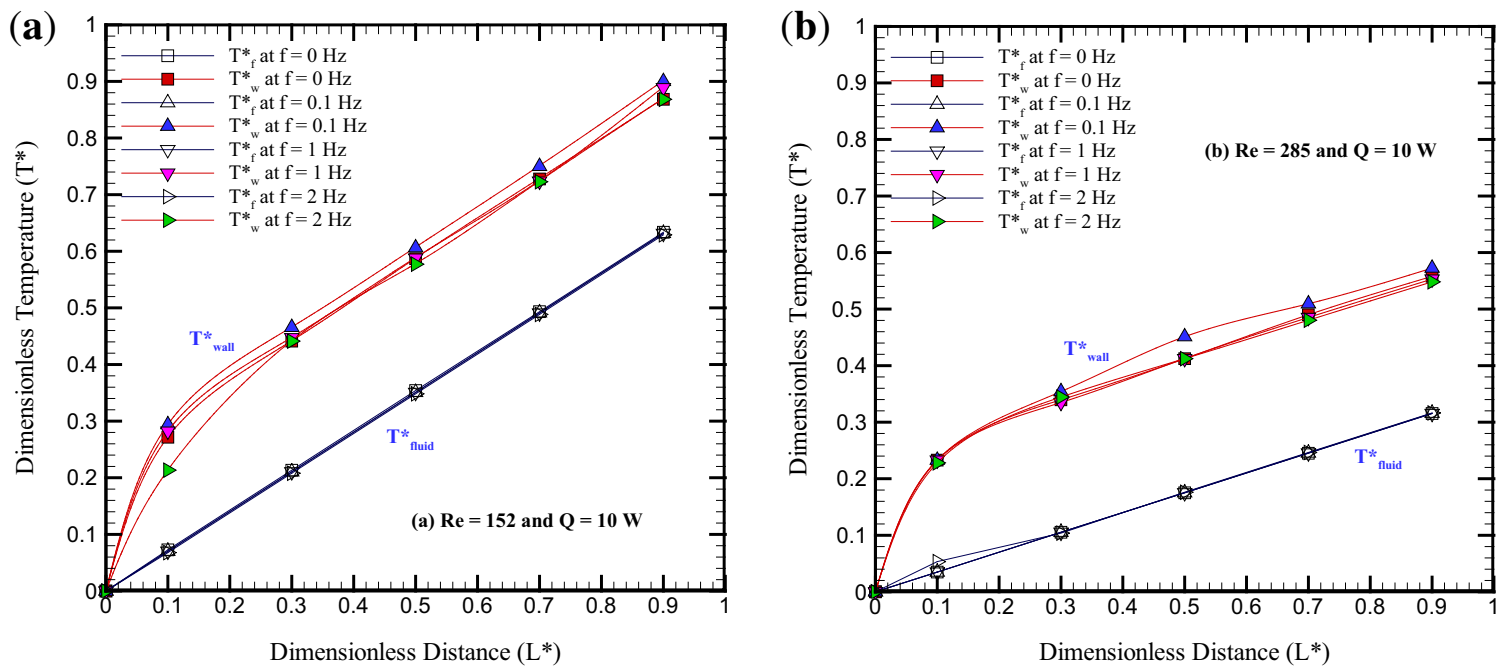

Figure 9. Dimensionless temperature versus dimensionless axial length of a minichannel for $Q=10 \mathrm{~W}$ and pulsation frequencies of 0 , $0.1,1$ and $2 \mathrm{~Hz}$ : (a) $R e=152$ and (b) $R e=285$.

which reduces the wall temperature, compared with noflow condition existing in pulsating flow. For imposed frequency of pulsation more than $1 \mathrm{~Hz}$, wall temperature is observed to decrease compared with the continuous flow case. This may be due to sudden impact of fluid on the channel wall, which carries more heat compared with continuous flow case. However, the increment and decrement in wall temperature are observed to be negligible compared to continuous flow through the channel.

Local Nusselt number variation as a function of inverse Graetz number for various imposed frequencies of pulsation $(0.1,1$ and $2 \mathrm{~Hz})$ at $R e=152$ and $R e=285$ are shown in figure 10. For Nusselt number calculation in each case, time-averaged flow rate is used. Nusselt number is observed to be higher at the entry of the heated section, which reduces along the length of the channel. Nusselt number is observed to increase with increase in imposed frequency up to $1 \mathrm{~Hz}$. For imposed frequency of $1 \mathrm{~Hz}$, Nusselt number is observed to coincide with Nusselt number observed for continuous flow $(0 \mathrm{~Hz})$. Heat transfer enhancement is found to be negligible (less than 1\%) for pulsation frequency of $2 \mathrm{~Hz}$ compared to continuous flow case. This shows the marginal enhancement of heat transfer due to pulsating liquid flow over continuous liquid flow for the imposed frequency of pulsation beyond $1 \mathrm{~Hz}$. Hence, pulsation frequency of $1 \mathrm{~Hz}$ can be set as the threshold frequency for
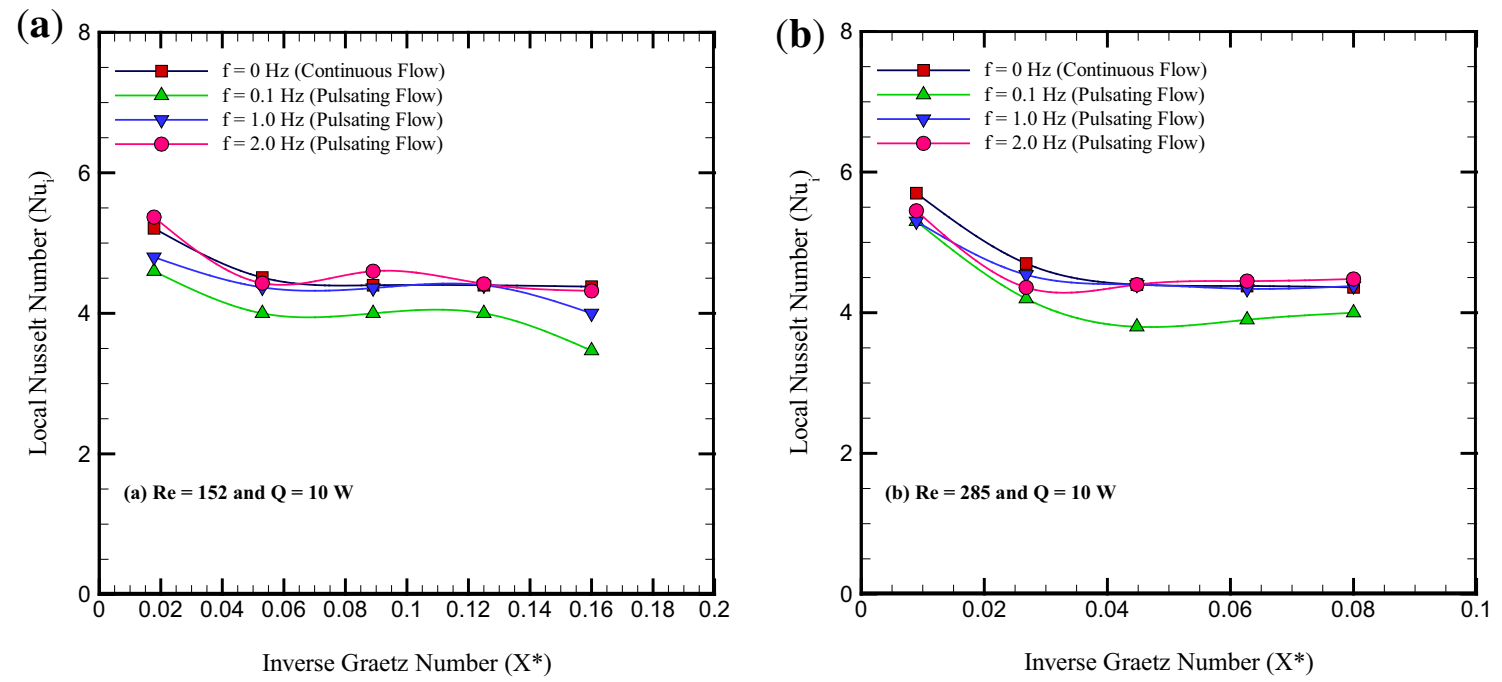

Figure 10. Local Nusselt number variation as a function of inverse Graetz number for $Q=10 \mathrm{~W}$ and pulsation frequencies of $0,0.1,1$ and $2 \mathrm{~Hz}$ : (a) $R e=152$ and (b) $R e=285$. 
Table 2. Different flow variables used in Taylor bubble flow.

\begin{tabular}{lcc}
\hline Time averaged gas flow rate $Q_{g}(\mathrm{ml} / \mathrm{min})$ & 10 & 10 \\
Time averaged liquid flow rate $Q_{l}(\mathrm{ml} / \mathrm{min})$ & 10 & 15 \\
Homogeneous void fraction $(\beta)$ & 0.5 & 0.39 \\
Superficial gas velocity $U_{s g}(\mathrm{~m} / \mathrm{s})$ & 0.0472 & 0.0472 \\
Superficial liquid velocity $U_{s l}(\mathrm{~m} / \mathrm{s})$ & 0.09443 & 0.0708 \\
Superficial mixture velocity $U_{t p}=U_{s l}+U_{s g}(\mathrm{~m} / \mathrm{s})$ & 302 & 0.118 \\
Two-phase Reynolds number $R e_{t p}=\frac{\rho_{l} U_{t p} d_{h}}{\mu_{t p}}$ & & 372
\end{tabular}

Table 3. Pulsation parameters.

\begin{tabular}{lccc}
\hline Imposed pulsation $(\mathrm{Hz})$ & 0.25 & 0.5 & 1 \\
Womersley number & 1.39 & 1.88 & 2.65 \\
Imposed time scale (s) & 4 & 2 & 1 \\
\hline
\end{tabular}

pulsating laminar liquid flow to enhance heat transfer compared with continuous flow through a minichannel.

\subsection{Adiabatic CTB and PTB}

Taylor bubble flow is a subset of gas-liquid two-phase flow and is observed at low superficial gas and liquid velocity. Continuous and PTB flow through a $2.12 \mathrm{~mm}$ minichannel is experimentally investigated. Two-phase flow parameters considered for the investigations are tabulated in table 2. PTB flow is generated through a liquid phase and a pulse generator circuit while gas phase is continuous throughout the experiments. Imposed and thermal diffusivity time scale for imposed pulsation is tabulated in table 3 .

It is worth noting here that heat transfer is attenuated for pulsating single-phase liquid flow compared with singlephase continuous flow with pulsation frequency up to $1 \mathrm{~Hz}$. Hence, pulsation frequency range is selected to be less than $1 \mathrm{~Hz}$ to investigate the pulsating two-phase Taylor bubble flow. Figures 11 and 12 show the continuous and PTB flow observed for two-phase Reynolds number of 302 and 372, respectively. In case of PTB flow, flow patterns observed during $\mathrm{ON}$ cycle and OFF cycle for pulsation frequency of $0.25,0.5$ and $1 \mathrm{~Hz}$ are separately shown.

The distribution of lengths of Taylor bubbles $\left(L_{b}\right)$ and liquid slugs $\left(L_{s}\right)$ for CTB and PTB observed for two-phase

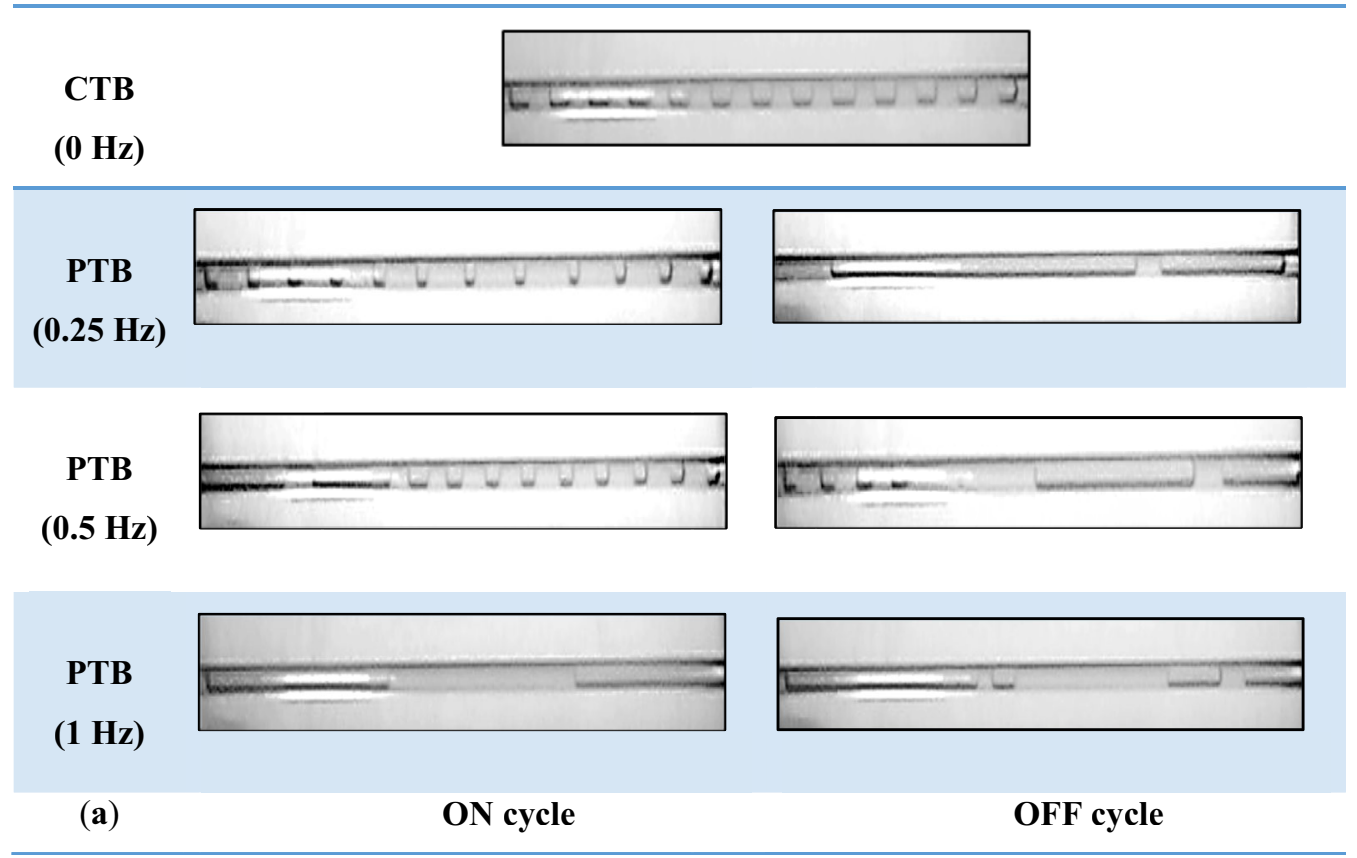

Figure 11. Flow patterns observed for continuous and pulsating Taylor bubble flow for pulsation frequency of $0,0.25,0.5$ and $1 \mathrm{~Hz}$ for $R e_{t p}=302$. 


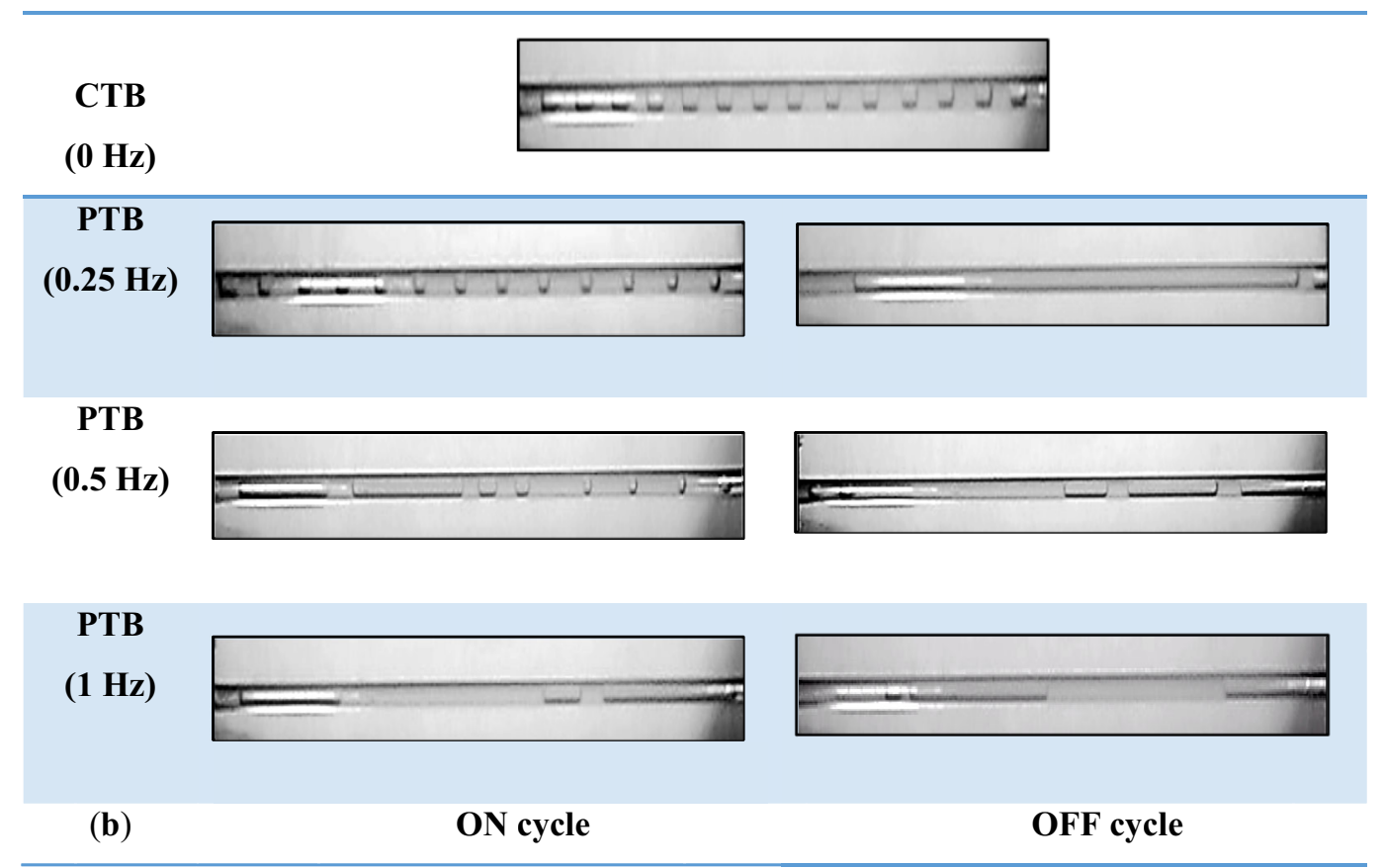

Figure 12. Flow patterns observed for continuous and pulsating Taylor bubble flow for pulsation frequency of $0,0.25,0.5$ and $1 \mathrm{~Hz}$ for $R e_{t p}=372$.

Reynolds number of 302 and 372 are shown in figures 13 and 14, respectively. Bubble numbers shown on the abscissa represent the successive Taylor bubbles tracked, which travel one after another during the Taylor bubble flow. In PTB flow, liquid slug length is observed to increase as compared with Taylor bubble length for the pulsation frequency of 0.25 and $0.5 \mathrm{~Hz}$. This is due to the sudden increase in liquid flow rate during $\mathrm{ON}$ cycle, which increases the liquid hold-up. Moreover, gas phase flow is continuous while liquid phase flow is intermittent through the channel for PTB. During the ON cycle, liquid phase continues to flow through the channel while it stops completely during the OFF cycle. Sudden increase in Taylor bubble length represents the OFF cycle wherein increase in void fraction increases the length of Taylor bubble. The Taylor bubble is observed to regain its original length during the next ON cycle. With increase in imposed frequency, imposed time scale reduces, which gives less time for Taylor bubble and liquid slug to regain their original length observed during continuous flow. Hence, the lengths of the Taylor bubbles and liquid slugs become more chaotic.

\subsection{Diabatic CTB and PTB}

This section discusses the influence of imposed frequency of pulsation on heat transfer induced by two-phase flow in a minichannel. The experiments are performed for heat input of $10 \mathrm{~W}$ and two-phase Reynolds number of 302 and 372. Dimensionless temperature distribution and Nusselt number for continuous single-phase liquid flow and twophase Taylor bubble flow are shown, respectively, in figure $15 \mathrm{a}$ and $\mathrm{b}$. It is observed that the Taylor bubble is responsible for reduction in axial wall temperature compared with single-phase flow for the same liquid flow rate $(10 \mathrm{ml})$. At the same time, the difference between wall temperature and fluid temperature is observed to decrease axially for Taylor bubble flow compared with single-phase liquid flow as shown in figure 15a. This is due to the reason that when liquid slug is trapped between Taylor bubbles, the localized radial mixing in liquid slug is significantly improved and heat transfer is enhanced between the wall and the fluid in the liquid slug. The enhancement in heat transfer is observed to be almost 1.4 times in CTB flow as compared with single-phase liquid flow as shown in figure $15 \mathrm{~b}$.

The experiments are extended to investigate the influence of pulsation frequency on heat transfer induced by two-phase flow through a circular minichannel. Pulsation frequencies of $0.25,0.5$ and $1 \mathrm{~Hz}$ are considered for the liquid flow while gas phase is kept continuous. Heat input is kept constant at $10 \mathrm{~W}$ and Reynolds numbers are calculated as 302 and 372 . The influence on wall and fluid temperatures along the axial length as a function of pulsation frequency for $R e_{t p}=302$ and 372 is 
CTB

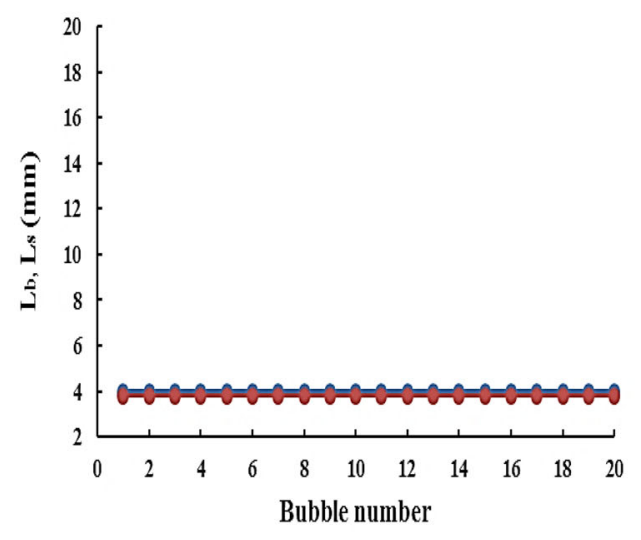

(a) CTB (0 Hz)

$\operatorname{PTB}(0.5 \mathrm{~Hz})$

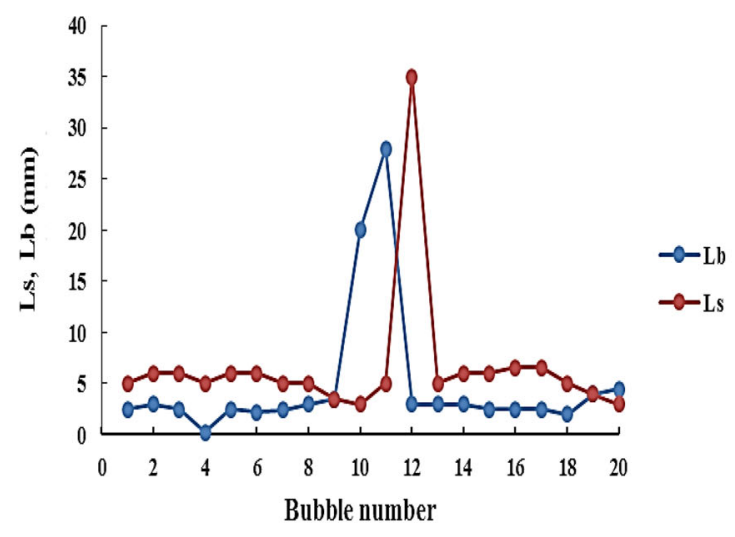

(c) PTB (0.5 Hz)
$\operatorname{PTB}(0.25 \mathrm{~Hz})$

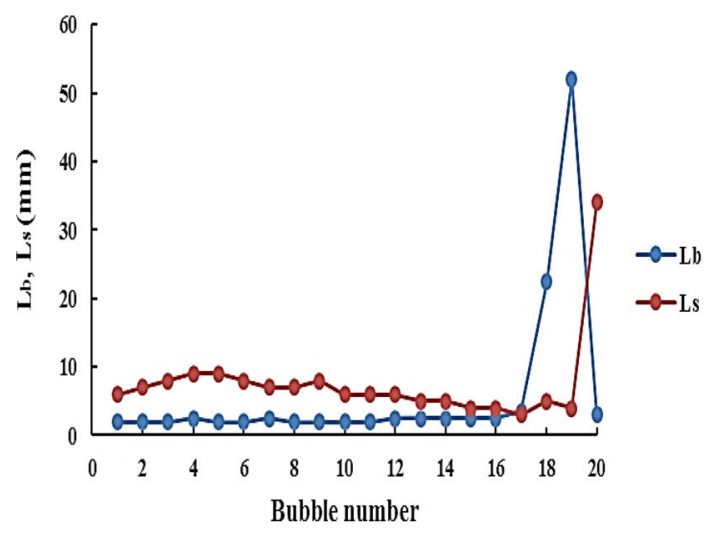

(b) PTB (0.25 Hz)

PTB (1 Hz)

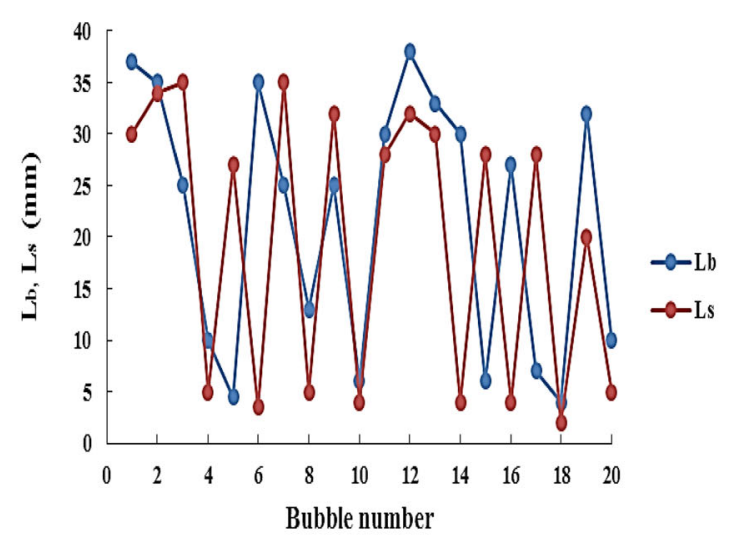

(d) PTB (1 Hz)

Figure 13. Distribution of lengths of Taylor bubbles and liquid slugs obtained for CTB and PTB flow at $R e_{t p}=302$.

shown in figure 16a and $\mathrm{b}$, respectively. It is observed that increase in pulsation frequency increases the wall temperature for PTB flow compared with CTB flow. Moreover, the difference between wall temperature and bulk fluid temperature is also observed to increase with increase in pulsation frequency. Nusselt number as a function of inverse Graetz number and pulsation frequency for $R e_{t p}=302$ and 372 is shown in figure 17a and b, respectively. Heat transfer is observed to increase with two-phase Reynolds number, though heat transfer decreases with increase in pulsation frequency. As discussed earlier, enhancement in heat transfer depends upon sequential appearance of liquid slug to come in contact with channel wall, which happens in continuous two-phase flow only. However, gas bubble length is observed to increase during PTB flow, which often comes in contact with channel wall. Due to lower heat capacity of gas phase compared with liquid phase, wall temperature is observed to increase in PTB flow. Increase in imposed frequency of pulsation creates abnormality in lengths of gas bubbles and liquid slugs. Hence, at $f=0.25 \mathrm{~Hz}$, heat transfer enhancement is observed over single-phase flow. On the contrary, heat transfer in PTB flow is attenuated compared with CTB flow. For pulsation frequency of 0.5 and $1 \mathrm{~Hz}$, heat transfer in PTB flow is observed to decrease compared with single-phase flow.

\section{Summary and conclusions}

The present paper discusses the influence of pulsation frequency on single-phase and Taylor bubble flow under adiabatic and diabatic flow conditions through a 
CTB

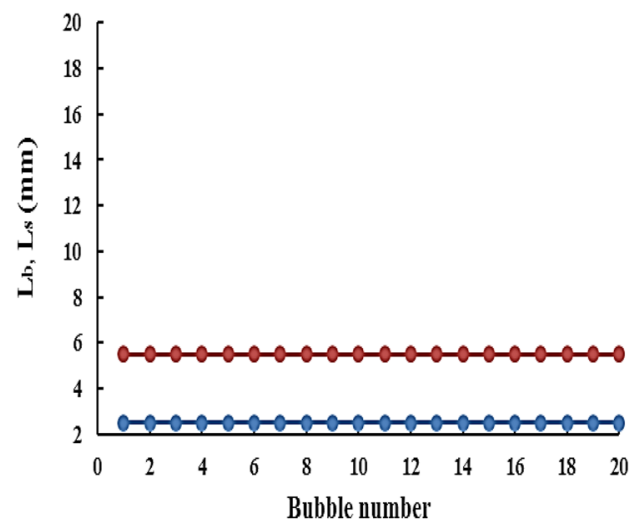

(a) CTB

PTB $(0.5 \mathrm{~Hz})$

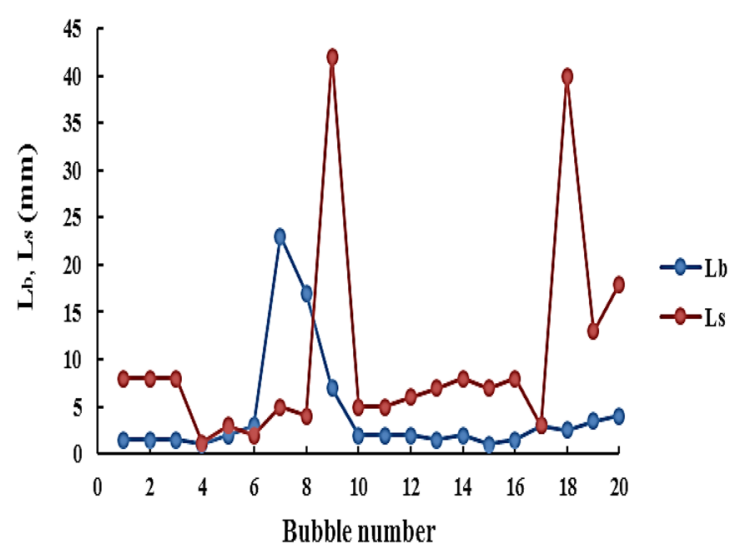

(c) PTB (0.5 Hz)
PTB $(0.25 \mathrm{~Hz})$

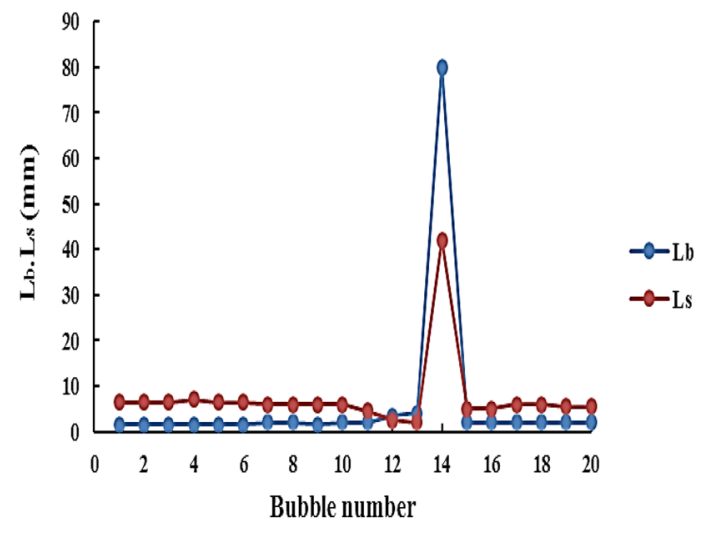

(b) PTB (0.25 Hz)

PTB (1 Hz)

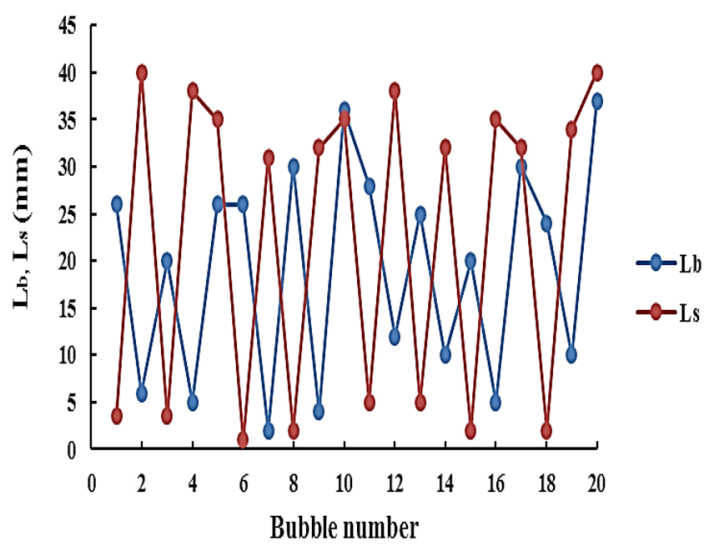

(d) PTB (1 Hz)

Figure 14. Distribution of lengths of Taylor bubbles and liquid slugs obtained for CTB and PTB flow at $R e_{t p}=372$.

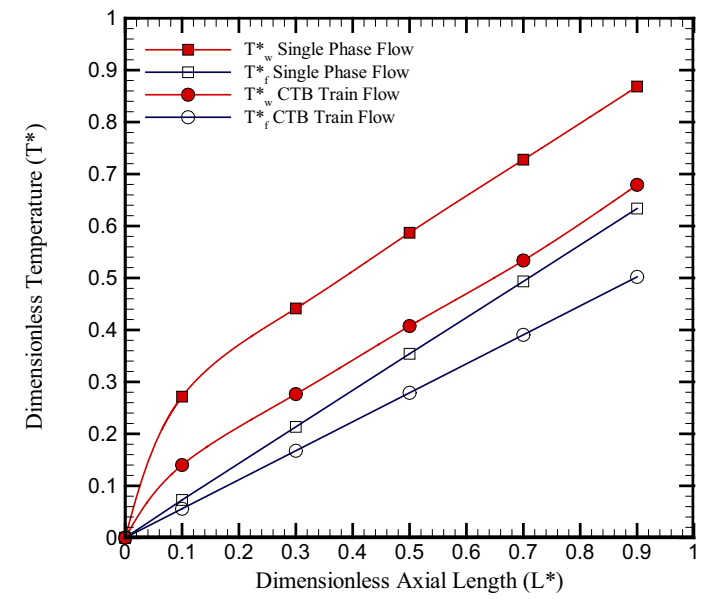

(a) Axial temperature distribution

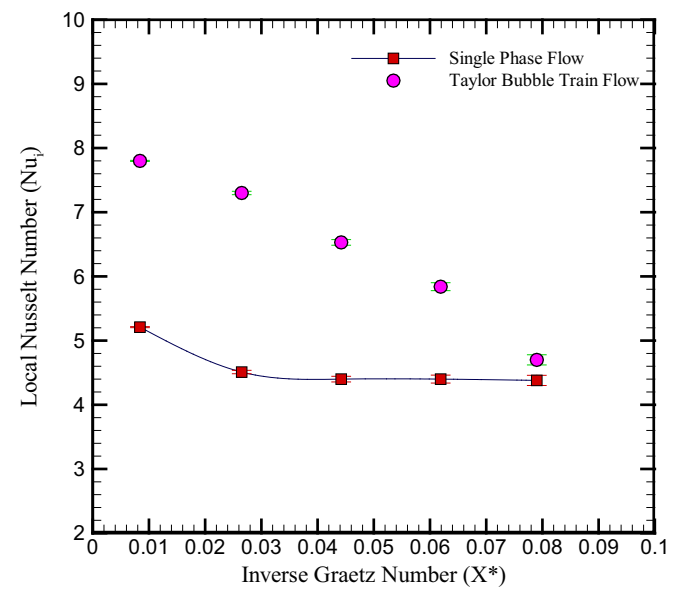

(b) Nusselt number variation

Figure 15. (a) Axial temperature distribution and (b) Nusselt number variation for continuous liquid flow and Taylor bubble flow (CTB). 

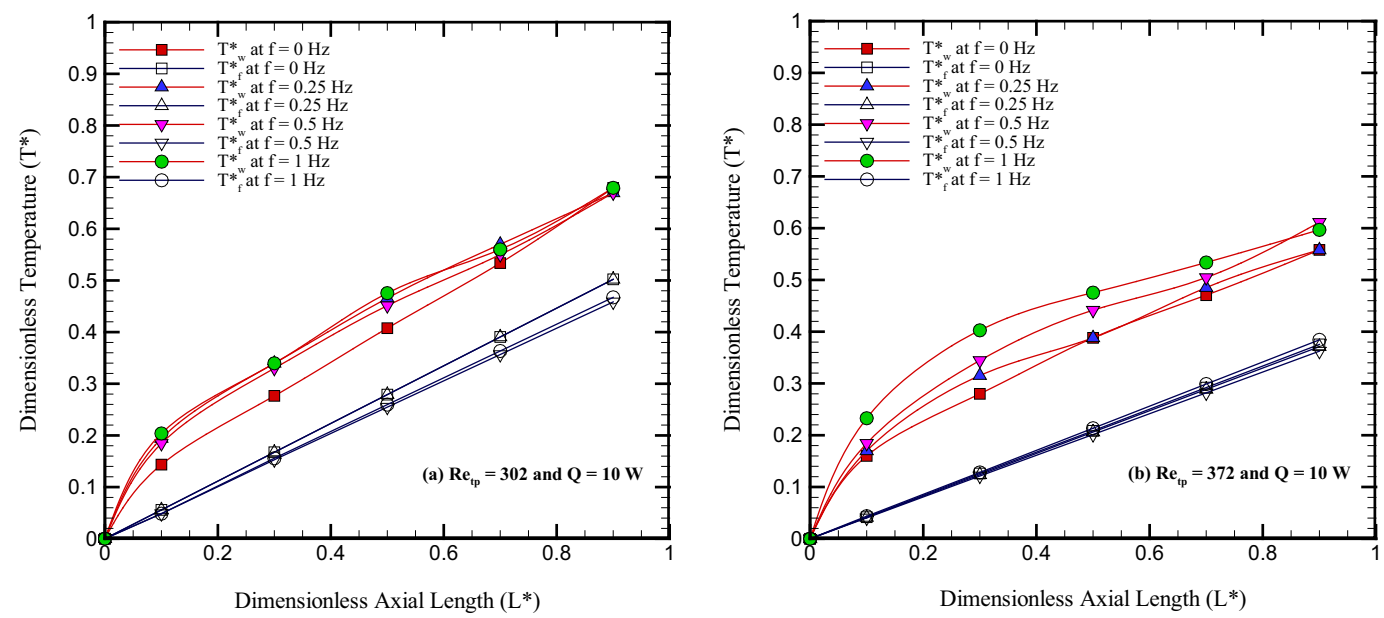

Figure 16. Axial temperature distribution for CTB and PTB: (a) $R e_{t p}=302$ and (b) $R e_{t p}=372$.
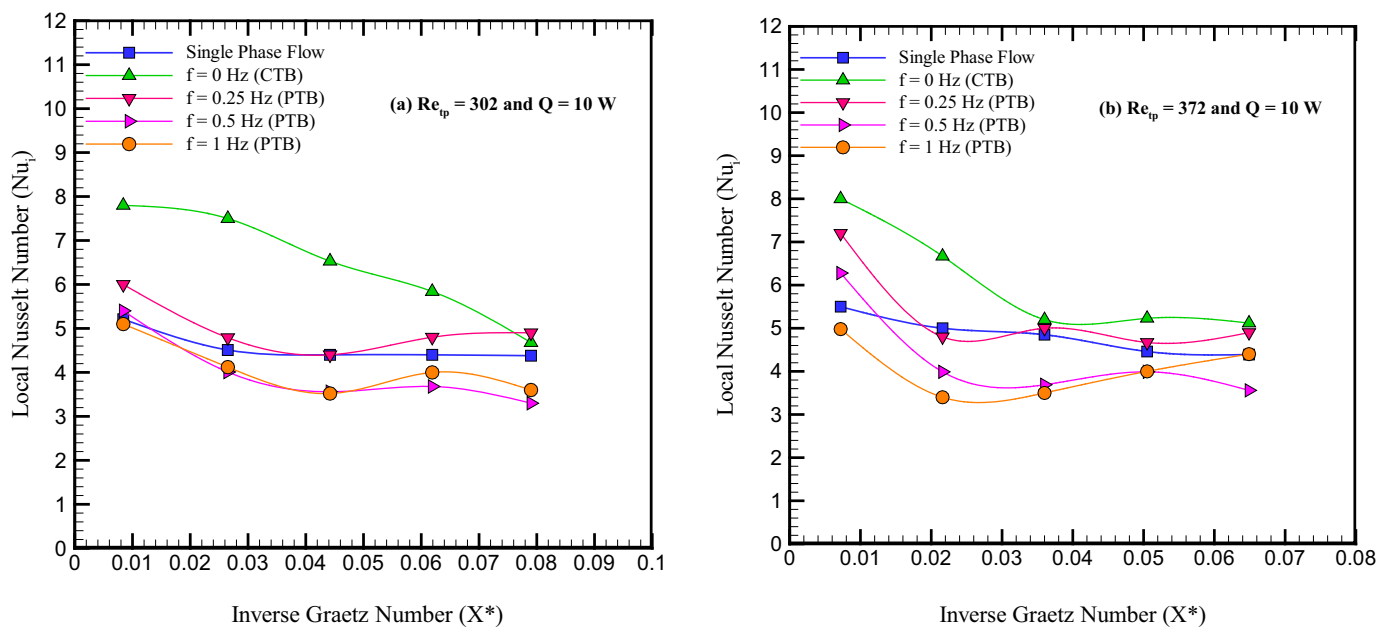

Figure 17. Local Nusselt number variation for CTB and PTB: (a) $R e_{t p}=302$ and (b) $R e_{t p}=372$.

$2.12 \mathrm{~mm}$ circular minichannel. The conclusions drawn out of the experimental investigations are as follows:

1. For pulsating single-phase liquid flow, the pulsation frequency of $1 \mathrm{~Hz}$ is found to be the threshold frequency since, at this frequency, Nusselt number agrees well with Nusselt number observed for continuous flow. Negligible heat transfer enhancement (less than 1\%) is observed for pulsation frequency of $2 \mathrm{~Hz}$. This shows practically the absence of significance of pulsating laminar liquid flow for engineering application against the continuous liquid flow through a minichannel.

2. In PTB flow, the flow rates of gas and liquid significantly influence the lengths of Taylor bubbles and liquid slugs. Increase in pulsation frequency of liquid flow increases the length of Taylor bubble compared with the length of liquid slug. The lengths of the Taylor bubbles and liquid slugs become more chaotic with pulsation frequency of $1 \mathrm{~Hz}$.

3. For PTB flow, increment in pulsation frequency up to $1 \mathrm{~Hz}$ reduces heat transfer compared with CTB flow. The heat transfer is observed to be attenuated by $35 \%$ with pulsation frequency of $1 \mathrm{~Hz}$ compared with CTB flow. This indicates that liquid slug distribution and the length of Taylor bubbles under pulsation are the important parameters to understand the thermal performance of PHPs.

4. The findings of the present investigations could be helpful to understand complex thermo-hydrodynamics of the PHP and to develop a mathematical model that incorporates the PTB flow through a capillary-sized minichannel. 


\section{Acknowledgements}

The authors would like to thank the authorities of the Sardar Vallabhbhai National Institute of Technology, Surat, for providing financial support for the development of Advanced Fluid Dynamics Lab, where this minichannelbased experiments were conducted.

\section{List of symbols}

c specific heat, $\mathrm{J} \mathrm{kg}^{-1} \mathrm{~K}^{-1}$

$d_{h}$ diameter of circular pipe, $\mathrm{m}$

$f$ frequency, $\mathrm{Hz}$

$h$ heat transfer coefficient, $\mathrm{W} \mathrm{m}{ }^{-1} \mathrm{~K}^{-1}$

$k$ thermal conductivity, $\mathrm{W} \mathrm{m}{ }^{-2} \mathrm{~K}^{-1}$

$L \quad$ length of heating section, $\mathrm{m}$

$L^{*} \quad$ non-dimensional axial length

$m$ mass flow rate, $\mathrm{kg} \mathrm{s}^{-1}$

$Q$ heat input, W

$q^{\prime}$ heat flux, $\mathrm{W} \mathrm{m}^{-2}$

$t$ time, s

$T$ imposed time period of fluctuation, $\mathrm{s}$

$T^{*}$ non-dimensional time period

$T_{f}^{*} \quad$ non-dimensional fluid temperature

$T_{w}^{*}$ non-dimensional wall temperature

$U$ velocity, $\mathrm{m} \mathrm{s}^{-1}$

$t_{c}$ thermal diffusivity time scale, $\mathrm{s}$

$x$ distance from heating section

\section{Greek symbol}

$\omega$ angular velocity, $\operatorname{rad~s}^{-1}$

$\alpha$ thermal diffusivity, $\mathrm{m}^{2} \mathrm{~s}^{-1}$

$\mu$ dynamic viscosity, $\mathrm{Pa} \mathrm{s}$

$\rho$ mass density, $\mathrm{kg} \mathrm{m}^{-3}$

$\beta$ homogeneous void fraction

\section{Non-dimensional numbers}

Re Reynolds number

$\mathrm{Nu}$ Nusselt number

$W_{o} \quad$ Womersley number $\left(0.5 d_{h} \sqrt{\frac{\omega}{v}}\right)$

$x^{*} \quad$ inverse Graetz number

\section{Subscripts}

$g$ gas (air) $l \quad$ liquid

tp two phase

$s l \quad$ superficial liquid

$s g$ superficial gas

\section{Superscripts}

* dimensionless

\section{References}

[1] Akachi H 1990 Patent No. 4,921,041, May 1, United States of America

[2] Akachi H 1993 Patent No. 5,219,020, June 15, United States of America

[3] Zhang Y and Faghri A 2002 Heat transfer in pulsating heat pipe with open end. Int. J. Heat Mass Transf. 45: 755-764

[4] Khandekar S, Gautam A P and Sharma P K 2009 Multiple quasi-steady states in a closed loop pulsating heat pipe. Int. J. Therm. Sci. 48: 535-546

[5] Khandekar S and Groll M 2004 An insight into thermo-hydraulic coupling in pulsating heat pipe. Int. J. Therm. Sci. 43(1): $13-20$

[6] Patel V M, Gaurav and Mehta H B 2017 Influence of working fluids on startup mechanism and thermal performance of a closed loop pulsating heat pipe. Appl. Therm. Eng. 110: 1568-1577

[7] Zhang Y and Faghri A 2008 Advances and unresolved issues in pulsating heat pipe. Heat Transf. Eng. 29(1): 20-44

[8] Mehta B and Khandekar S 2014 Taylor bubble flows and heat transfer in the context of pulsating heat pipes. Int. J. Heat Mass Transf. 79: 279-290

[9] Mehta H B and Banerjee J 2016 Experimental investigations on thermo-hydrodynamics of continuous Taylor bubble flow through minichannel. Int. J. Heat Mass Transf. 94: 119-137

[10] Kline S J and McClintock K N 1953 The descriptions of uncertainties in single sample experiments. Mech. Eng. 75: 3-8

[11] Muzychka Y S and Yovanovich M M 2004. Force convection heat transfer in the combined entry region of non-circular ducts. ASME J. Heat Transf. 126: 54-61

[12] Womersley J R 1955 Method for the calculation of velocity rate of flow and viscous drag in arteries when the pressure gradient is known. J. Physiol. 127: 553-563

[13] Yu J and Zhao T S 2004 An analytical study of pulsating laminar heat convection in circular tube with constant heat flux. Int. J. Heat Mass Transf. 47: 5297-5301 